\title{
Article \\ Djnedd4L Is Required for Head Regeneration by Regulating Stem Cell Maintenance in Planarians
}

\author{
Qingnan Tian ${ }^{1,+}$, Yujia Sun ${ }^{1,+}$, Tingting Gao ${ }^{1}$, Jiaxin $\mathrm{Li}^{1}{ }^{1}$, Huimin Fang ${ }^{1, *}$ and Shoutao Zhang ${ }^{1,2, *}$ \\ 1 School of Life Sciences, Zhengzhou University, Zhengzhou 450001, China; tianqn@zzu.edu.cn (Q.T.); \\ yujiasun903@163.com (Y.S.); gaotingting406@163.com (T.G.); ljx15203995016@163.com (J.L.) \\ 2 Henan Key Laboratory of Bioactive Macromolecules, Zhengzhou 450001, China \\ * Correspondence: fanghm@zzu.edu.cn (H.F.); zhangst@zzu.edu.cn (S.Z.) \\ + These authors contributed equally to this work.
}

check for updates

Citation: Tian, Q.; Sun, Y.; Gao, T.; Li, J.; Fang, H.; Zhang, S. Djnedd4L Is Required for Head Regeneration by Regulating Stem Cell Maintenance in Planarians. Int. J. Mol. Sci. 2021, 22, 11707. https://doi.org/10.3390/ ijms222111707

Academic Editor: Antonino Germana

Received: 15 September 2021

Accepted: 24 October 2021

Published: 28 October 2021

Publisher's Note: MDPI stays neutral with regard to jurisdictional claims in published maps and institutional affiliations.

Copyright: (c) 2021 by the authors. Licensee MDPI, Basel, Switzerland. This article is an open access article distributed under the terms and conditions of the Creative Commons Attribution (CC BY) license (https:// creativecommons.org/licenses/by/ $4.0 /)$.

\begin{abstract}
SUMOylation and ubiquitylation are homologous processes catalyzed by homologous enzymes, and they are involved in nearly all aspects of eukaryotic biology. Planarians, which have the remarkable ability to regenerate their central nervous system (CNS), provide an excellent opportunity to investigate the molecular processes of CNS regeneration in vivo. In this study, we analyzed gene expression profiles during head regeneration with an RNA-seq-based screening approach and found that Djnedd4L and $D j u b c 9$ were required for head regeneration in planarians. RNA interference targeting of Djubc9 caused the phospho-H3 mitotic cells to decrease in quantity, or even become absent as a part of the Djubc9 RNAi phenotype, which also showed the collapse of the stem cell lineage along with the reduced expression of epidermal differentiation markers. Furthermore, we found that Djnedd4L RNAi induced increased cell division and promoted the premature differentiation during regeneration. Taken together, our findings show that Djubc9 and Djnedd $4 L$ are required for stem cell maintenance in the planarian Dugesia japonica, which helps to elucidate the role of SUMOylation and ubiquitylation in regulating the regeneration process.
\end{abstract}

Keywords: Djnedd4L; Djubc9; stem cells; regeneration; SUMOylation; ubiquitylation

\section{Background}

Protein ubiquitination is a multifaceted posttranslational modification that can lead to protein degradation by the $26 \mathrm{~S}$ proteasome [1]. Protein ubiquitination is attached to substrates by a mechanism that involves a number of factors, beginning with an E1 ubiquitin-activating enzyme that makes ubiquitin reactive. Activated ubiquitin is conjugated to an E2 ubiquitin conjugase, which interacts with an E3 ubiquitin ligase to transfer ubiquitin onto a target substrate [2-4]. The process of SUMOylation is similar to ubiquitylation, with small ubiquitin-like modifier (SUMO) attaching to substrates through an E1-activating enzyme, an E2-conjugating enzyme, and an E3-ligase [5]. Ubiquitination and SUMOylation covalently modify various target proteins in all eukaryotes. Depending on the targets, SUMOylation and ubiquitylation regulate various cellular mechanisms, such as protein-protein interactions, protein stability, subcellular localization, cell cycle regulation, and transcription factor activity [4,6-9].

Freshwater planarian flatworms are among the few animals with the remarkable ability to regenerate any part of their body, including the central nervous system (CNS) from tissue fragments originating from almost any part of their bodies [10-14]. These properties require a pool of adult stem cells named neoblasts $[15,16]$. Neoblasts can migrate toward the wound site after injury and differentiate into any planarian cell type to regenerate the missing target tissues. Thus, in the process of regeneration, neoblasts must receive proper instructions to correctly achieve the replacement of missing tissues [14,17-20]. However, how ubiquitylation participates in planarian regeneration has not been thoroughly elucidated to date. 
In this study, we characterize the planarian homologue of Djnedd4L, a member of E3 ubiquitin ligases, and Djubc9, a sole E2-conjugating enzyme gene, in Dugesia japonica. RNAi knockdown of Djubc9 leads to a lysis phenotype in both regenerating and intact planarians. We observed a depletion of cell division along with a loss of stem cell progeny markers. RNAi knockdown of Dineddll4 results in the absence of the anterior marker and the reduced expression levels of the head makers. Our results suggest that Djubc9 is required for the maintenance of stem cells in planarians and Djnedd $4 L$ is required for the reestablishment of anterior domain identities during planarian regeneration.

\section{Results}

2.1. Transcriptome Analysis Clarified the Genes Involved in Head Regeneration in the Planarian Dugesia japonica

To obtain the gene expression profiles during planarian head regeneration, we analyzed the transcriptomes of planarians 3 days after head amputation (Figure 1A). The anterior pre-pharyngeal fragments frozen immediately after decapitation were used as controls (0 dpa). Using the assembly genome of Dugesia japonica as reference (BioProject accession: PRJNA580305), a total of 23497 genes were generated by sequencing on an Illumina Genome Analyzer II, and 10576 genes were annotated in the MAKER genome annotation. By comparing the transcriptomes of head regeneration and control tissues, we identified 763 downregulated transcripts (fold change $<0.5$ ) and 379 upregulated transcripts (fold change > 2) (Figure 1B,C). The Kyoto Encyclopedia of Genes and Genomes (KEGG) functions analysis of the differentially expressed genes (DEGs) revealed that "Metabolic pathways" had the highest number of genes (Figure 1D). Interestingly, we found that the genes coding ubiquitination and SUMOylation enzymes were DEGs during head regeneration (Supplementary Material).

A

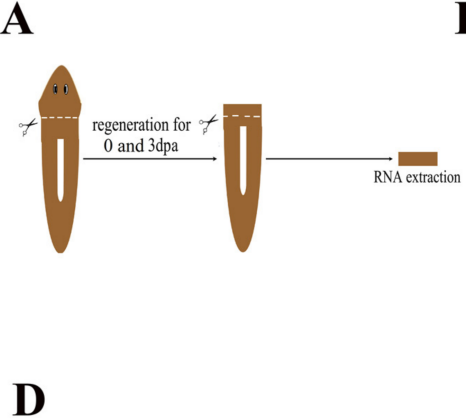

B

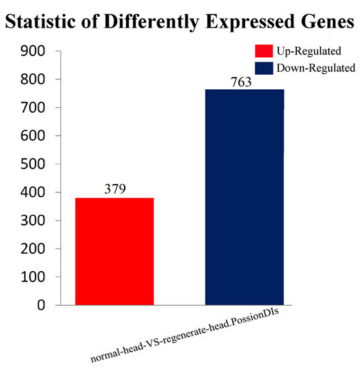

C

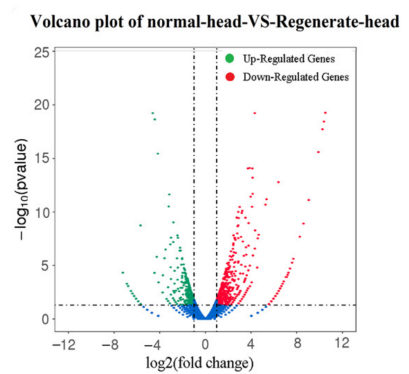

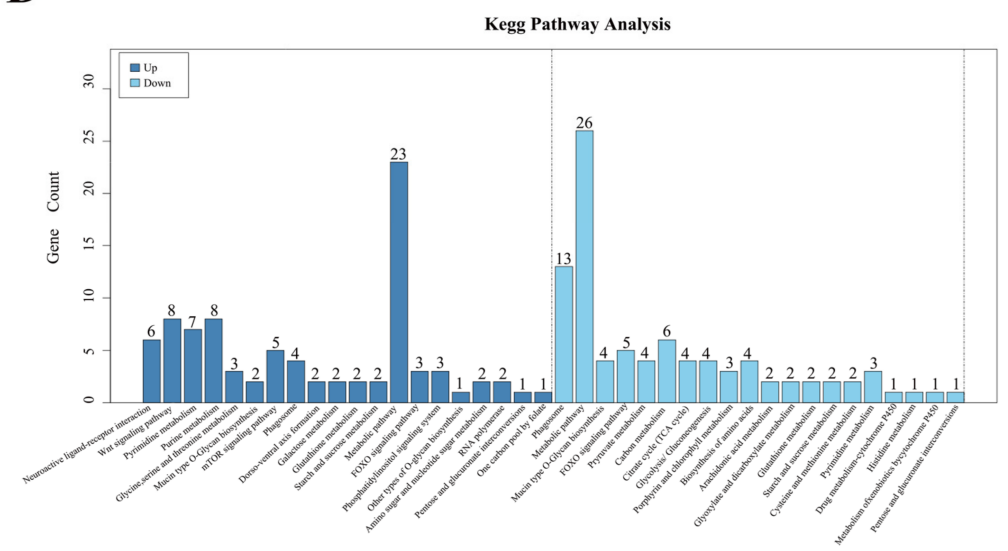

Figure 1. The head regeneration transcriptome of the planarian Dugesia japonica. (A) Schematic overview of the RNA sequencing approach. (B,C) Differentially expressed genes detection (DEGs). (B) Summary of DEGs. The X axis represents comparison samples. The $\mathrm{Y}$ axis represents DEG numbers. (C) Volcano plot of DEGs. The Y axis represents $-\log 10$ transformed significance. The $X$ axis represents $\log 2$ transformed fold change. (D) The Kyoto Encyclopedia of Genes and Genomes (KEGG) function annotation of DEGs. 


\subsection{Djnedd4L and Djubc9 RNAi Cause Head Regeneration Defects}

Next, we performed an RNAi screen to identify the genes need for planarian head regeneration and found that Djnedd $4 L$ and $D j u b c 9$ were required for planarian regeneration. After 8 days of regeneration, the control animals had a well-formed head and tail $(10 / 10)$ and a pair of eyes that could be observed clearly. In contrast, following Djubc 9 RNAi, the anterior trunk and tail fragments formed a significantly reduced blastema and lacked eyes (20/20) (Figure 2A). In addition to the reduced blastema, the expression of synapsin, a CNS marker [21-23], showed that although the CNS regenerated a complete nerve cord, the cephalic brain did not form in the "anterior blastema" of the $u b c 9$ RNAi trunk and tail fragments (8/10) (Figure 2D). These results show that with Djubc9 (RNAi), the blastemas could not appropriately differentiate into the anterior region. In Djnedd4L RNAi-treated animals, the eyes could barely be observed and the triangular head could not form (Figure 2D). The CNS could not regenerate completely in the newly formed head in the trunk and tail fragments (Figure 2D).

Whole-mount RNA in situ hybridization (WISH) was performed in intact and regenerative worms to analyze the expression patterns of Djnedd $4 L$ and $D j u b c 9$ in planarians. Worms were amputated pre- and post-pharyngeally and fixed at 1 and $3 \mathrm{~d}$ post amputation. We observed a ubiquitous expression throughout the body with no specific localization to tissue or organs in intact animals (Figure 2B). The expression level of Djubc9 was higher in the wound region during regeneration (Figure 2B), which is consistent with the transcriptomes of head regeneration (Figure S2). Similarly, the intact animals stained for Djnedd4L also showed ubiquitous expression consistent with the expression patterns of Djubc9 in intact and regenerating animals (Figure $2 \mathrm{C}$ ). These data raise the possibility that $D j u b c 9$ and Djnedd $4 L$ might be required not only for the regeneration process. Next, we tested whether Djnedd $4 L$ and Djubc9 were also required for tissue homeostasis (Figure 2E). We found that only Djubc9 (RNAi) has an effect on the tissue homeostasis. At day 10, the border of the head also began to curl and lyse (18/20) in Djubc9 (RNAi) animals. At day 16, the lysis region extended to the whole body (17/20) (Figure 2E). We propose that knockdown of Djubc9 or Djnedd $4 L$ may disrupt stem cell maintenance during tissue regeneration. Therefore, we next analyzed the effect of Djubc9 and Djnedd $4 \mathrm{~L}$ on cell division and the maintenance of stem cells during the course of the $c d c 42$ RNAi and Djnedd $4 L$ RNAi phenotypes.

\subsection{Djubc9 (RNAi) Phenotype Defects Indicate That Djubc9 Is Required for the Maintenance of Stem Cells}

To assess whether $D j u b c 9$ is required for cell division, we performed an analysis of the mitotic response by quantifying $\mathrm{pH}$ 3-positive cells in intact animals. The $\mathrm{pH}$ 3-positive cells in Djubc9 RNAi animals were comparable with those of the controls in the first three days. After 5 days of RNAi, a progressive reduction in $\mathrm{pH}$ 3-positive cells in intact animals could be detected (Figure 3A). These results suggest the Djubc9 RNAi might disrupt the maintenance of stem cell progeny. Therefore, we next examined the stem cell lineage makers in Djubc9 RNAi animals. We used three identified lineage markers of planarian stem cells and two differentiated cell markers to identify the cell types that were affected by hypo-proliferation, including stem cell (Djpiwi-1), early progeny (prog), late progeny (AGAT1), later stage (Vimentin), and mature cell (Lamin B) [24-33]. We examined the expression of lineage production for the $D j u b c 9$ phenotype. A significant reduction in the expression of stem cell-specific markers was detected. The expression of Djpiwi-A, as well as of prog, and AGAT1, was nearly absent (Figure 3B-D). The expression levels of two differentiated cell markers (Vimentin and Lamin B) for the epidermal lineage were also decreased (Figure 3E,F). These results suggest that Djubc9 is needed for stem cells and progeny, as $D j u b c 9 R N A i$ animals lost their stem cells and progeny. 
A

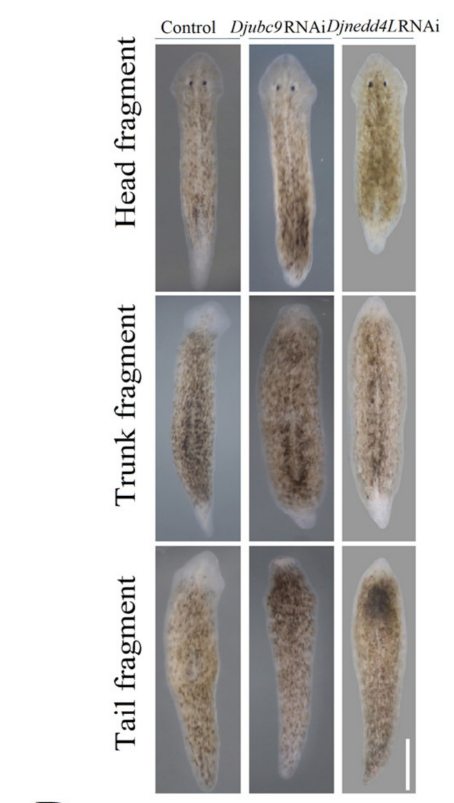

D

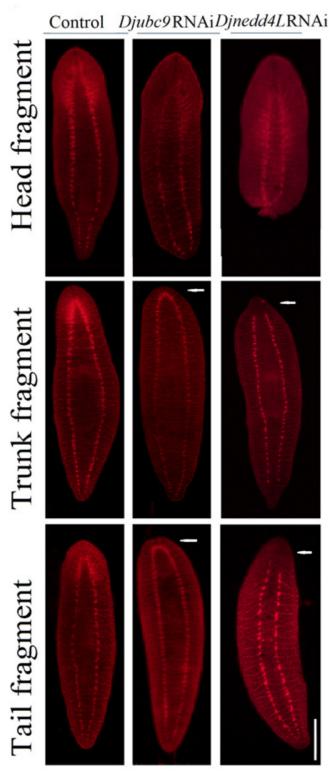

B

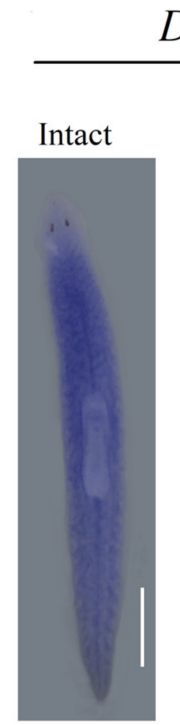

Djubc9
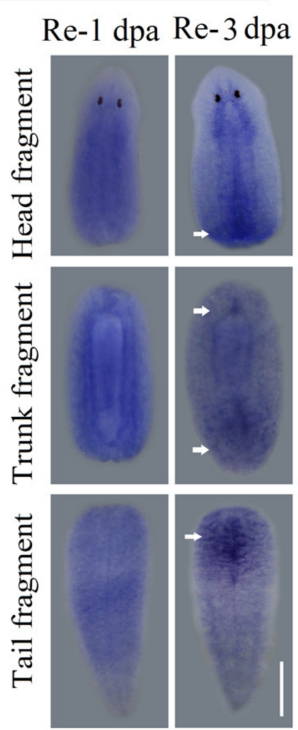

E

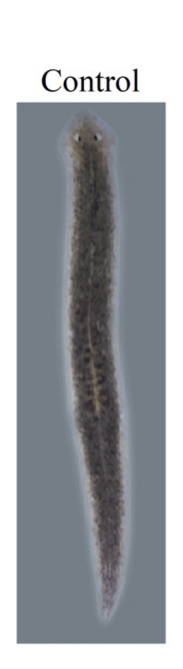

\section{Djubc9 RNAi}

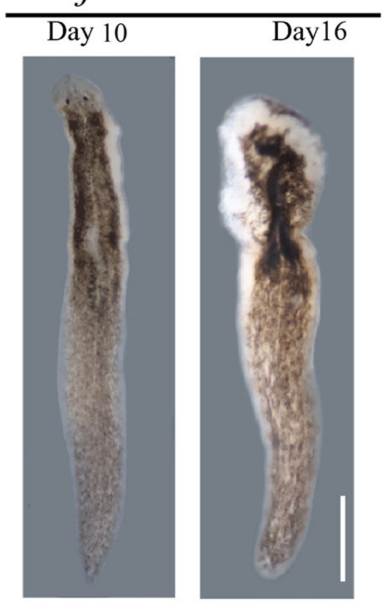

C

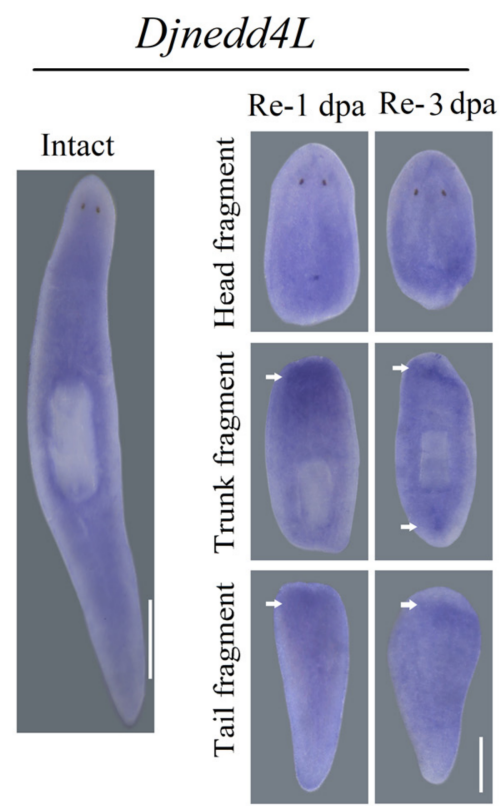

Djnedd4L RNAi.

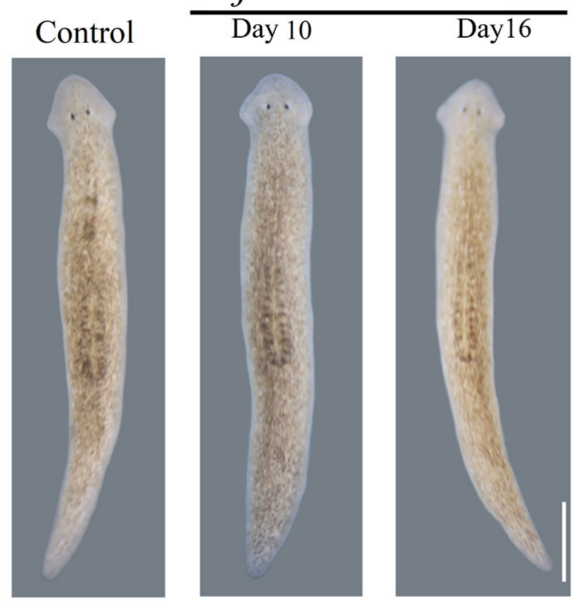

Figure 2. Effects of $D j u b c 9$ RNAi and Djnedd4L RNAi during regeneration. (A) Regeneration defects caused by Djubc9 RNAi and Djnedd4L RNAi. (B,C) Expression patterns of Djubc9 $(\mathbf{B})$ and Djnedd4L $(\mathbf{C})$ in intact and regenerating animals $(\mathrm{n}=20)$ assessed by whole-mount in situ hybridization. The worms were fixed 1 and $3 \mathrm{~d}$ after amputation. The arrowheads point to the higher expression of Djnedd $4 L$ and $D j u b c 9$ in wound region. (D) The CNS defects caused by Djubc9 RNAi and Djnedd4L RNAi. The whole-mount immunostainings were performed with primary anti-synapsin. The arrows point to under-developed brains and to a blastema without a brain. (E) Intact phenotypes caused Djubc9 RNAi and Djnedd4L RNAi. A stereotypical lysis phenotype beginning around day 10 in Djubc9 RNAi animals, which proceeded until worms completely curled and lysed at about day 16. Scale bars: $300 \mu \mathrm{m}$. 

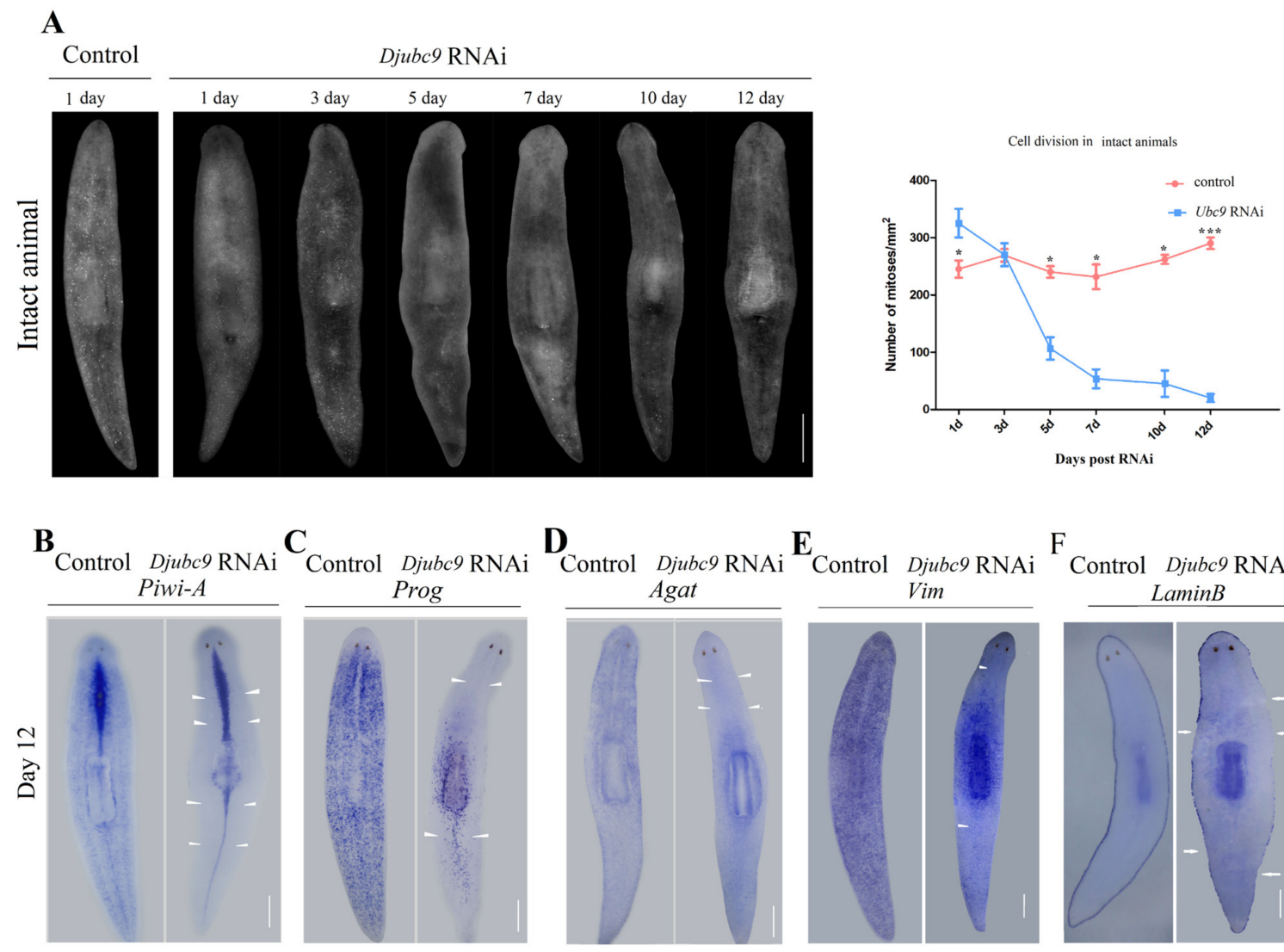

$\mathbf{E}_{\text {Control }}$ Djubc 9 RNAi ${ }^{\mathrm{F}}$

Control Djubc 9 RNAi
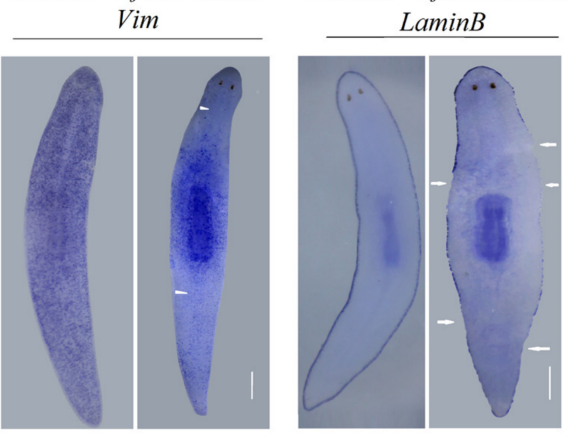

Figure 3. Analysis of the effect of $D j u b c 9$ RNAi on cell division and stem cell lineage. (A) Analysis of the effect of Djubc9 RNAi on cell division. Intact worms were stained following RNAi injections using the marker H3ser10p, which marks cells during the G2/M cell cycle transition. (B-F) The expression patterns of epidermal lineage markers of stem cells (piwi) (B), early progeny (prog) (C), late progeny $(A G A T 1)(\mathbf{D})$, later stage (Vimentin) (E) and mature cells (Lamin B) (F) in control and Djubc9 RNAi animals. Statistical differences are measured by Student's $t$-test and error bars indicate s.e.m. ${ }^{*} p<0.05$, *** $p<0.001$ (Student's $t$ test). For each time point, $\mathrm{n}=15$ with three experimental replicates. Scale bars: $200 \mu \mathrm{m}$.

\subsection{The Effect Djnedd4L (RNAi) on Cell Division and Differentiation during Regeneration}

The expression of the CNS marker PC-2 showed that the Djnedd4L RNAi animals formed a blastema without a brain (Figure 4A). To further evaluate whether Djnedd4L RNAi only affects head regeneration, we performed in situ hybridization to detect the head and tail markers, secreted frizzled protein $1(s F R P 1)$ and frizzled-like protein $\mathrm{T}(f z T)$ in trunk fragments [34]. Eight days after amputation, the control animals showed normal sFRP1 expression patterns in the anterior head regions. In contrast, the Djnedd4L RNAi animals almost lost the expression of $s F R P 1$ (Figure $4 \mathrm{~B}$ ). Similarly, the tail marker $f z T$ also showed decreased expression compared to the controls (Figure 4C). Next, we used qRT-PCR to analyze the effect of Djnedd $4 L$ on the expression levels of multiple position control genes (PCGs) during regeneration of trunk fragments after Djnedd4L RNAi. Total RNA used in qRT-PCR was isolated from trunk fragments; $s F R P-1$, chat, otxa, and notum were selected as head PCGs, and AxinB, wntP, fzt, and Djabdba were selected as tail PCGs [14,35-41]. After 4 days of RNAi, the expression levels of the head PCGs were reduced in the Djnedd $4 L$ RNAi animals compared to the controls. Similarly, the expression levels of the tail PCGs were also decreased (Figure 5D). These results further indicate that Djnedd4L is required not only for head regeneration but also tail regeneration.

As stem cell function is essential to planarian regeneration, it was possible that Djnedd4L (RNAi) disrupted planarian stem cell lineages. Thus, we first evaluated mitotic activity by whole-mount immunofluorescence for phosphorylated histone H3 (H3ser10p), a marker of dividing cells beginning at the G2 /M cell phase, in Djnedd4L (RNAi) re- 
generating trunks 8 days post-amputation. We found that the number of phospho-H3+ cells in Djnedd4L (RNAi) animals were significantly increased compared to the controls (Figure 5A). Correspondingly, the expression levels of piwi-1-marked undifferentiated neoblasts were also increased after Djnedd 4 L RNAi (Figure 5B). Consistent with this, the expression patterns of prog and agat, which labeled the early progeny and late progeny, were increased after Djnedd4L RNAi (Figure 5C,D). Similarly, the expression of vim in differentiated epidermal cells not integrated into the epidermis was also significantly increased (Figure 5E). However, the marker for mature epidermal cells, lamin B, expression in Djnedd4L (RNAi) animals was significantly decreased (Figure 5F). Taken together, our findings suggest that Djnedd4L RNAi induced increased cell division and promoted the premature differentiation during regeneration. These results further indicate that Djnedd $4 L$ participates in tissue regeneration by regulating stem cell proliferation and differentiation.

A

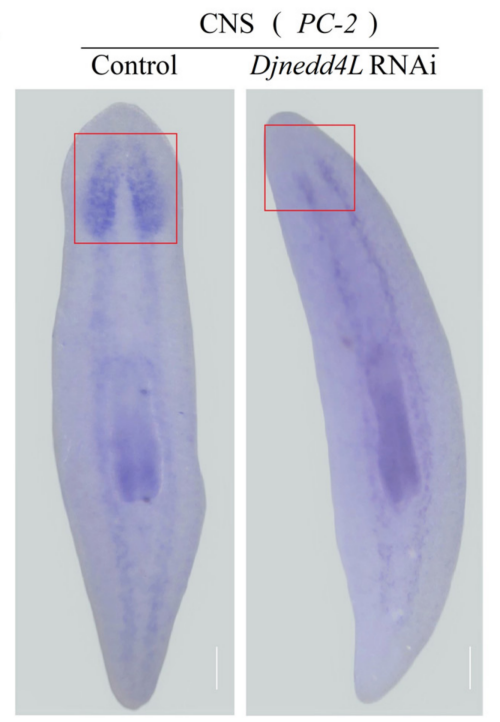

$\mathrm{D}$

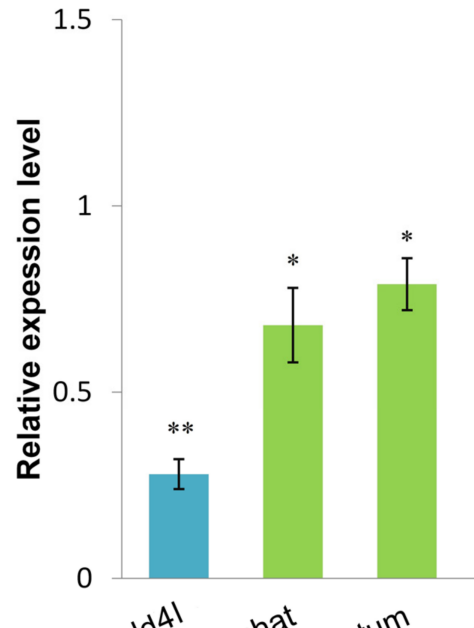

B

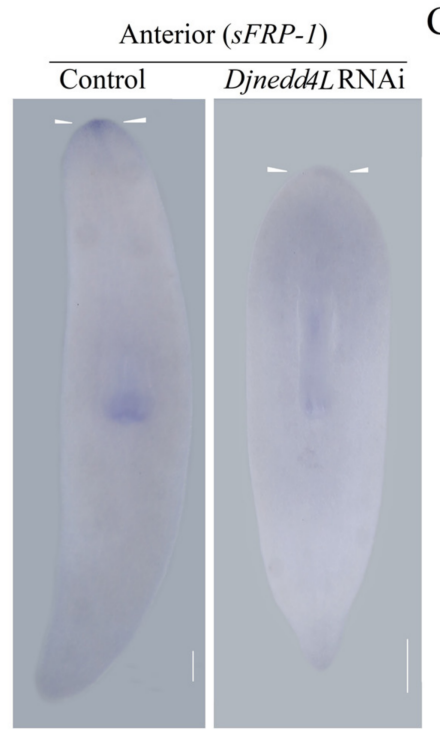

$\mathrm{C}$

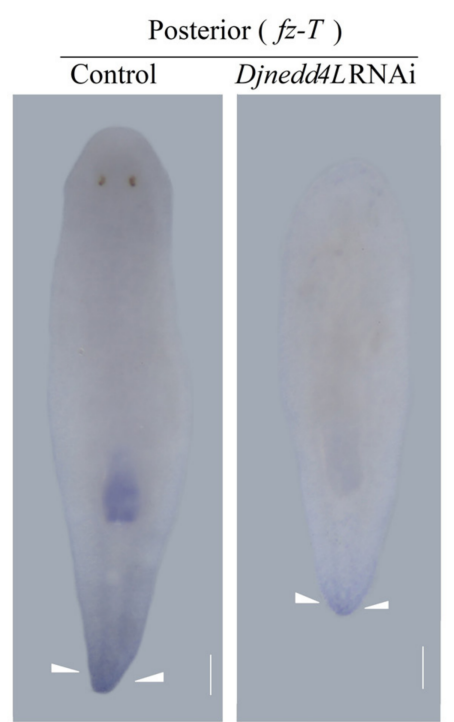

- Djnedd4L

nead markers

- Tail markers

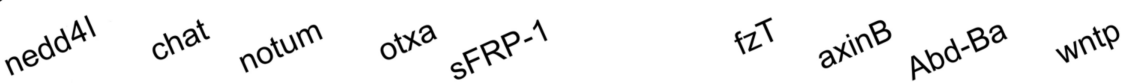

Figure 4. Analysis of the effect of Djnedd4L RNAi on the A-P polarity identities. (A-C) Characterization by in situ detection of CNS marker PC-2, anterior marker sFRP-1, and posterior marker $f z-T$. The cephalic brains are in red-shaded boxes (A). The arrows indicate the expression patterns of $s F R P-1$ (B) and the normal expression patterns of $f z-T$ (C). (D) Relative gene expression levels of head and tail markers in Djnedd4L RNAi animals. Error bars represent SDs of three biological replicates. Data were analyzed by Student's $t$-test. ${ }^{*} p<0.05$; ${ }^{* *} p<0.01$; differences are considered significant at $p<0.05$. Scale bars: $200 \mu \mathrm{m}$. 
A

Control Djnedd4LRNAi
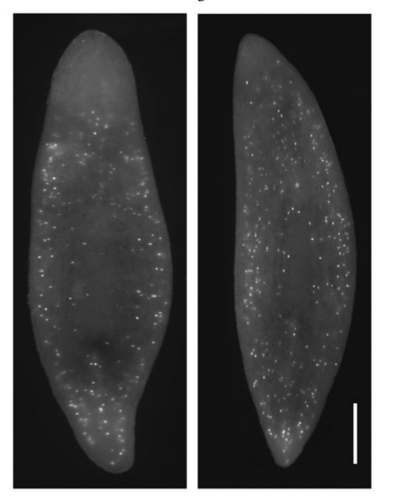

$\mathrm{D}$

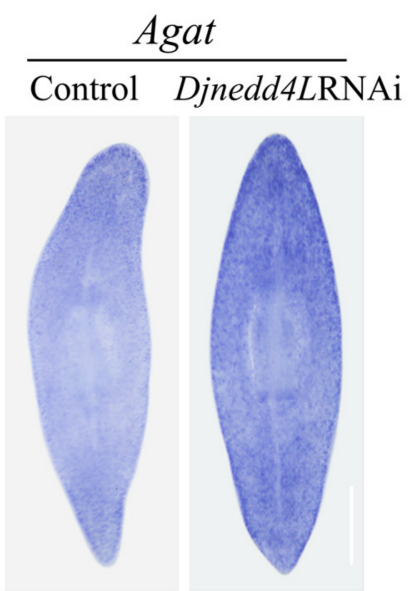

B

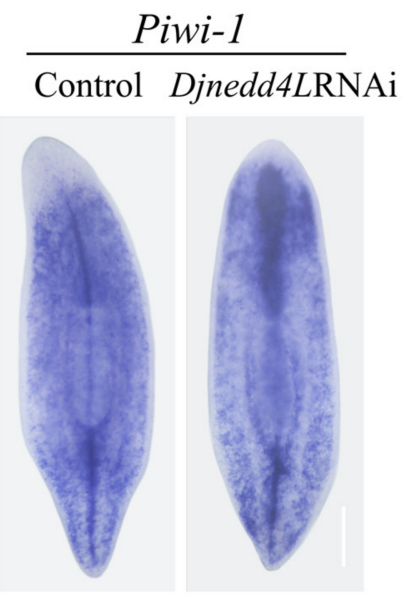

$\mathrm{C}$

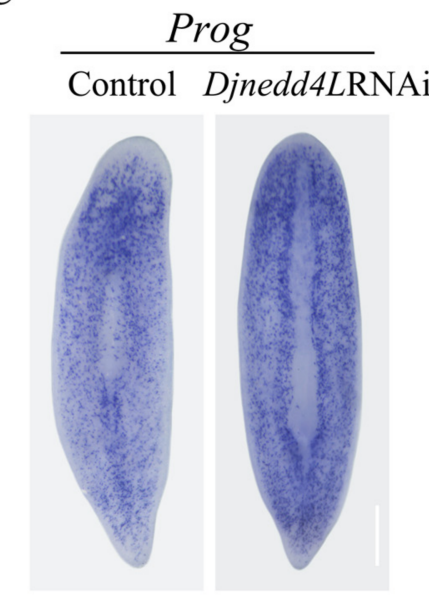

E

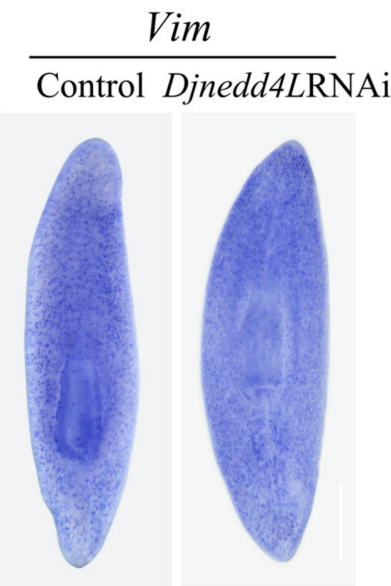

$\mathrm{F}$

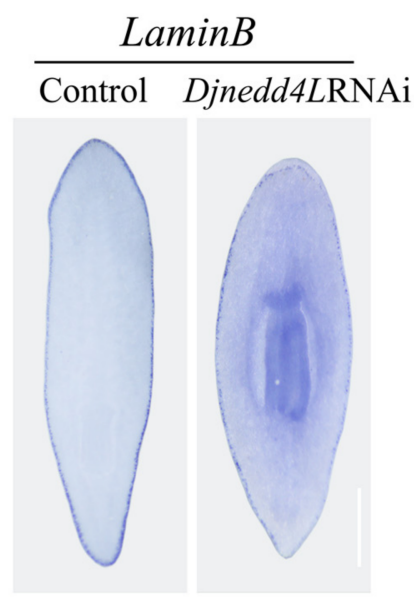

Figure 5. Analysis of cell division and stem cell lineage in the Djnedd4L (RNAi) phenotype. (A) Immunostaining with anti-phospho-histone 3 of trunk fragments. Worms were amputated pre- and post-pharyngeally and fixed at $8 \mathrm{dpa}$. (B-D) Analysis of stem cells (piwi-1), early progeny (prog), and late progeny (AGAT) markers by whole-mount in situ hybridization (WISH) in regenerating trunk fragments in RNAi animals. (E,F) examination of epidermal cell (vim) and mature epidermal cells (lamin B). Error bars indicate s.e.m. $\mathrm{n}>20$ with at least three experimental replicates. ${ }^{*} p<0.05$. Scale bars: $300 \mu \mathrm{m}$.

\section{Discussion}

Neurodegenerative diseases can cause irreversible damage to the CNS. Therefore, it is crucial to understand the basic molecular mechanisms needed to induce and promote the reestablishment of nervous system function. Planarians, which have a remarkable ability to regenerate their CNS, provide an excellent opportunity to analyze this process in vivo. To shed light onto the control of CNS regeneration, we analyzed the gene expression profiles with an RNA-seq-based screening approach and found that Djnedd $4 L$ and Djubc9 were required for $\mathrm{CNS}$ regeneration in planarians.

The ubiquitin system is an essential cellular pathway in protein regulation. In another other model planarian species, Schmidtea mediterranea, Smedubc9 has been proven to control stem cell proliferation and regional cell death [42]. Consistent with the studies in Schmidtea mediterranea, the $\mathrm{pH}$ 3-positive cells in the Djubc9 RNAi animals were nearly absent in both regenerated and intact planarians (Figures $3 \mathrm{~A}$ and S2), in which the stem cell lineage collapsed along with the reduced expression of epidermal differentiation markers (Figure 3B-F). These data suggest that SUMOylation is required for the maintenance of stem cells in both Schmidtea mediterranea and Dugesia japonica. 
In previous reports, specific roles for ubiquitin ligases have been characterized in planarian regeneration. Some E3 ubiquitin ligases, such as huwe1, wwp1, trip12, and Cullin-RING ubiquitin ligase (CRL) complexes, have been proven to be required for tissue regeneration by regulating the neoblast population and tissue specification [43,44]. In this study, we characterized the role of the HECT-domain E3 ligase, nedd4L, in tissue renewal. We found that the expression of the head marker sFRP-1 was absent in the Djnedd4L RNAi animals in the regenerating animals. The expression levels of head and tail markers were both reduced in the intact Djnedd 4 L RNAi animals, suggesting that Djnedd4L is required for not only head regeneration but also tail regeneration. In addition to this, similar to the phenotypes observed after knockdown of HUWE1 in S. mediterranea, Djnedd4L RNAi induced hyper-proliferation and abnormal differentiation of stem cells were observed, suggesting that it is a regulator of cell cycle. Consistent with this, nedd4L has been reported as a tumor suppressor by regulating several protein targets, such as LGR5 and DVL2 [45,46]. Thus, our studies provide an excellent model to investigate the mechanisms of nedd4L regulating the cell cycle during stem cell self-renewal and differentiation.

Planarians are an excellent model system for experimental dissection of processes, such as tissue regeneration and tissue patterning. Planarian regeneration requires neoblasts to produces new cells of blastemas, which generate the replacement parts needed for regeneration. The fate specification in planarian regeneration primarily occurs in neoblasts, which are the source of new cells in planarian regeneration to produce all adult cell types. The neoblast's capacity for renewal and differentiation suggests that the neoblast population contains stem cells [47]. During the processes of homeostasis and regeneration, stem cells must not only continually maintain the rates of cell division but also properly induce differentiated progeny into new tissues. Our findings show that SUMOylation and ubiquitylation are required for regeneration by regulating the maintenance of stem cell in the planarian Dugesia japonica, which helps to elucidate the role of SUMOylation and ubiquitylation in regulating the regeneration process.

\section{Materials and Methods}

\subsection{Planarian Culture}

All experiments were performed with a clonal strain of the planarian Dugesia japonica. Planarians were maintained as previously described [48]. The animals were starved for at least 7 days prior to the experiments.

\section{2. cDNA Clones and RNAi Experiments}

$D j u b c 9$ and Djnedd $4 L$ were amplified from cDNA in a constructed library of expressed sequence tags (ESTs) (Figure S1). dsRNA was synthesized as previously described [49,50]. In the case of single RNAi experiments, $2 \mu \mathrm{g} / \mu \mathrm{L}$ of dsRNA was injected into the animals using microinjection twice a day for three days. dsRNA against the green fluorescent protein (GFP) sequence was injected into the control animals. The animals were transversely cut into three fragments anterior and posterior to the pharynx and allowed to regenerate for the indicated number of days. The primers for cloning and dsRNA generation are listed in Table S1.

\subsection{In Situ Hybridization}

Whole-mount in situ hybridizations (WISHs) were performed as previously described with digoxigenin-labeled probes [51]. The samples were hybridized with a DIG-labeled probe at $56{ }^{\circ} \mathrm{C}$ for $17 \mathrm{~h}$. Subsequently, colorimetry (NBT/BCIP) was used to detect the signal.

\subsection{Whole-Mount Immunostaining}

Whole-mount immunostaining was performed as previously described [52]. The animals were killed with 5\% NAC in phosphate-buffered saline (PBS) for 5 min at room temperature and washed four times with PBS containing 0.1\% TritonX-100 (PBST). The an- 
imals were then fixed in PBST containing $4 \%$ paraformaldehyde, and cold $100 \% \mathrm{MeOH}$ for $1 \mathrm{~h}$. Next, animals were blocked with $10 \%$ goat serum in PBST for 2 to $4 \mathrm{~h}$ at $4{ }^{\circ} \mathrm{C}$ and incubated with primary anti-synapsin (1:100-1:500 Developmental Studies Hybridoma Bank) or anti-H3P (1:500; Millipore, Burlington, MA, USA, 05-817R) antibodies overnight. The secondary antibodies include goat anti-rabbit Alexa Fluor 568 (1:500; Invitrogen, Waltham, MA, USA, 11036) for anti-H3P, and goat anti-mouse Alexa Fluor 488 (1:500; Invitrogen, 673781) for anti-synapsin. Digital pictures were collected using NIS element software (Nikon, Tokyo, Japan).

\subsection{Quantitative Real-Time PCR Analysis of Gene Expression}

Quantitative real-time PCR was performed as previously described [49]. Total RNA was extracted from each pool of planarians using Trizol (TaKaRa, Gunma, Japan), and cDNA was generated from $1 \mu \mathrm{g}$ of total RNA with oligo-dT primers and reverse transcriptase (TaKaRa). Three samples were run in parallel for each condition and normalized to the expression of elongation factor 2 (EF-2). The primers used for quantitative real-time PCR are listed in Supplementary Table S1.

\subsection{Sample Collection and Head Regeneration RNA-Seq}

Regeneration was allowed to occur for 3 days for the preparation of the head regeneration sequencing libraries for RNA-Seq. Fragments were obtained by a second cut anterior to the pharynx. The anterior pre-pharyngeal fragments frozen immediately after decapitation were used as controls. Ten planarian prepharyngeal fragments were pooled. The libraries were sequenced on an Illumina Genome Analyzer II as previously described [53].

Supplementary Materials: The following are available online at https:/ / www.mdpi.com/article/ 10.3390 /ijms222111707/s1, Figure S1: Multiple sequence alignment of Djubc9 and Djnedd14 from Dugesia japonica, Homo sapiens, Mus musculus, Drosophila serrata, Xenopus laevis, and Danio rerio, Figure S2: Analysis of the effect of Djubc9 RNAi on cell division in regenerating fragments, Table S1: PCR primers used in this study.

Author Contributions: Conceptualization, H.F. and S.Z.; methodology, Q.T.; validation, Q.T., Y.S., T.G. and J.L.; formal analysis, Q.T.; investigation, Y.S.; resources, T.G.; data curation, Y.S.; writing—original draft preparation, T.G.; writing-review and editing, S.Z.; visualization, S.Z.; supervision, S.Z.; project administration, S.Z.; funding acquisition, Q.T. and S.Z. All authors have read and agreed to the published version of the manuscript.

Funding: This research was founded by National Natural Science Foundation of China (31970419, 31601867), Bingtuan Science and Technology Project (2019AB034), Scientific and technological innovation talents in Colleges of Henan (21HASTIT034), and Science and Technology Research Project of Henan (202102310151).

Data Availability Statement: All the data obtained in the current study are presented in this article. The RNA-Seq sequence raw data have been deposited at the National Center for Biotechnology Information (NCBI), Sequence Read Archive (SRA), under the Accession Number SAMN21193302.

Conflicts of Interest: The authors declare no competing financial interests.

\section{References}

1. Chen, C.; Matesic, L.E. The Nedd4-like family of E3 ubiquitin ligases and cancer. Cancer Metastasis Rev. 2007, $26,587-604$. [CrossRef]

2. Hershko, A.; Ciechanover, A. The ubiquitin system. Annu. Rev. Biochem. 1998, 67, 425-479. [CrossRef] [PubMed]

3. Swatek, K.N.; Komander, D. Ubiquitin modifications. Cell Res. 2016, 26, 399-422. [CrossRef]

4. Tsuchida, S.; Satoh, M.; Takiwaki, M.; Nomura, F. Ubiquitination in Periodontal Disease: A Review. Int. J. Mol. Sci. 2017, 18, 1476. [CrossRef] [PubMed]

5. Strand, N.S.; Allen, J.M.; Zayas, R.M. Post-translational regulation of planarian regeneration. Semin. Cell Dev. Biol. 2018, 87, 58-68. [CrossRef]

6. Gareau, J.R.; Lima, C.D. The SUMO pathway: Emerging mechanisms that shape specificity, conjugation and recognition. Nat. Rev. Mol. Cell Biol. 2010, 11, 861-871. [CrossRef] 
7. Geiss-Friedlander, R.; Melchior, F. Concepts in sumoylation: A decade on. Nat. Rev. Mol. Cell Biol. 2007, 8, 947-956. [CrossRef] [PubMed]

8. Hay, R.T. SUMO-specific proteases: A twist in the tail. Trends Cell Biol. 2007, 17, 370-376. [CrossRef]

9. Kim, K.I.; Baek, S.H. Small ubiquitin-like modifiers in cellular malignancy and metastasis. Int. Rev. Cell Mol. Biol. 2009, 273, 265-311. [PubMed]

10. Newmark, P.A.; Sanchez Alvarado, A. Not your father's planarian: A classic model enters the era of functional genomics. Nat. Rev. Genet. 2002, 3, 210-219. [CrossRef] [PubMed]

11. Reddien, P.W.; Sanchez Alvarado, A. Fundamentals of planarian regeneration. Annu. Rev. Cell Dev. Biol. 2004, 20, 725-757. [CrossRef]

12. Salo, E. The power of regeneration and the stem-cell kingdom: Freshwater planarians (Platyhelminthes). Bioessays 2006, 28, 546-559. [CrossRef] [PubMed]

13. Rossi, L.; Salvetti, A. Planarian stem cell niche, the challenge for understanding tissue regeneration. Semin Cell Dev. Biol. 2018, 87, 30-36. [CrossRef] [PubMed]

14. Sandmann, T.; Vogg, M.C.; Owlarn, S.; Boutros, M.; Bartscherer, K. The head-regeneration transcriptome of the planarian Schmidtea mediterranea. Genome Biol. 2011, 12, R76. [CrossRef]

15. Tanaka, E.M.; Reddien, P.W. The cellular basis for animal regeneration. Dev. Cell 2011, 21, 172-185. [CrossRef] [PubMed]

16. Wagner, D.E.; Wang, I.E.; Reddien, P.W. Clonogenic neoblasts are pluripotent adult stem cells that underlie planarian regeneration. Science 2011, 332, 811-816. [CrossRef] [PubMed]

17. Wagner, D.E.; Ho, J.J.; Reddien, P.W. Genetic regulators of a pluripotent adult stem cell system in planarians identified by RNAi and clonal analysis. Cell Stem. Cell 2012, 10, 299-311. [CrossRef]

18. Wenemoser, D.; Lapan, S.W.; Wilkinson, A.W.; Bell, G.W.; Reddien, P.W. A molecular wound response program associated with regeneration initiation in planarians. Genes Dev. 2012, 26, 988-1002. [CrossRef] [PubMed]

19. Malinowski, P.T.; Cochet-Escartin, O.; Kaj, K.J.; Ronan, E.; Groisman, A.; Diamond, P.H.; Collins, E.S. Mechanics dictate where and how freshwater planarians fission. Proc. Natl. Acad. Sci. USA 2017, 114, 10888-10893. [CrossRef]

20. Scimone, M.L.; Cote, L.E.; Reddien, P.W. Orthogonal muscle fibres have different instructive roles in planarian regeneration. Nature 2017, 551, 623-628. [CrossRef]

21. Cebria, F.; Kobayashi, C.; Umesono, Y.; Nakazawa, M.; Mineta, K.; Ikeo, K.; Gojobori, T.; Itoh, M.; Taira, M.; Sanchez Alvarado, A.; et al. FGFR-related gene nou-darake restricts brain tissues to the head region of planarians. Nature 2002, 419, 620-624. [CrossRef]

22. Cebria, F.; Newmark, P.A. Morphogenesis defects are associated with abnormal nervous system regeneration following roboA RNAi in planarians. Development 2007, 134, 833-837. [CrossRef]

23. Pearson, B.J.; Sanchez Alvarado, A. A planarian p53 homolog regulates proliferation and self-renewal in adult stem cell lineages. Development 2010, 137, 213-221. [CrossRef] [PubMed]

24. Eisenhoffer, G.T.; Kang, H.; Sanchez Alvarado, A. Molecular analysis of stem cells and their descendants during cell turnover and regeneration in the planarian Schmidtea mediterranea. Cell Stem Cell 2008, 3, 327-339. [CrossRef]

25. Tu, K.C.; Cheng, L.C.; Vu, H.T.; Lange, J.J.; McKinney, S.A.; Seidel, C.W.; Sanchez Alvarado, A. Egr-5 is a post-mitotic regulator of planarian epidermal differentiation. eLife 2015, 4, e10501. [CrossRef]

26. Zhu, S.J.; Hallows, S.E.; Currie, K.W.; Xu, C.; Pearson, B.J. A mex3 homolog is required for differentiation during planarian stem cell lineage development. eLife 2015, 4, e07025. [CrossRef] [PubMed]

27. Van Wolfswinkel, J.C.; Wagner, D.E.; Reddien, P.W. Single-cell analysis reveals functionally distinct classes within the planarian stem cell compartment. Cell Stem Cell 2014, 15, 326-339. [CrossRef] [PubMed]

28. Wurtzel, O.; Oderberg, I.M.; Reddien, P.W. Planarian Epidermal Stem Cells Respond to Positional Cues to Promote Cell-Type Diversity. Dev. Cell 2017, 40, 491-504.e5. [CrossRef]

29. Rossi, L.; Bonuccelli, L.; Iacopetti, P.; Evangelista, M.; Ghezzani, C.; Tana, L.; Salvetti, A. Prohibitin 2 regulates cell proliferation and mitochondrial cristae morphogenesis in planarian stem cells. Stem Cell Rev. 2014, 10, 871-887. [CrossRef] [PubMed]

30. Rossi, L.; Salvetti, A.; Lena, A.; Batistoni, R.; Deri, P.; Pugliesi, C.; Loreti, E.; Gremigni, V. DjPiwi-1, a member of the PAZ-Piwi gene family, defines a subpopulation of planarian stem cells. Dev. Genes Evol. 2006, 216, 335-346. [CrossRef]

31. Tian, Q.; Zhao, G.; Sun, Y.; Yuan, D.; Guo, Q.; Zhang, Y.; Liu, J.; Zhang, S. Exportin-1 is required for the maintenance of the planarian epidermal lineage. Int. J. Biol. Macromol. 2019, 126, 1050-1055. [CrossRef]

32. Shibata, N.; Hayashi, T.; Fukumura, R.; Fujii, J.; Kudome-Takamatsu, T.; Nishimura, O.; Sano, S.; Son, F.; Suzuki, N.; Araki, R.; et al. Comprehensive gene expression analyses in pluripotent stem cells of a planarian, Dugesia japonica. Int. J. Dev. Biol. 2012, 56, 93-102. [CrossRef]

33. Durant, F.; Morokuma, J.; Fields, C.; Williams, K.; Adams, D.S.; Levin, M. Long-Term, Stochastic Editing of Regenerative Anatomy via Targeting Endogenous Bioelectric Gradients. Biophys. J. 2017, 112, 2231-2243. [CrossRef]

34. Gurley, K.A.; Rink, J.C.; Sanchez Alvarado, A. Beta-catenin defines head versus tail identity during planarian regeneration and homeostasis. Science 2008, 319, 323-327. [CrossRef] [PubMed]

35. Reuter, H.; Marz, M.; Vogg, M.C.; Eccles, D.; Grifol-Boldu, L.; Wehner, D.; Owlarn, S.; Adell, T.; Weidinger, G.; Bartscherer, K. Beta-catenin-dependent control of positional information along the AP body axis in planarians involves a teashirt family member. Cell Rep. 2015, 10, 253-265. [CrossRef] [PubMed] 
36. Owen, J.H.; Wagner, D.E.; Chen, C.C.; Petersen, C.P.; Reddien, P.W. teashirt is required for head-versus-tail regeneration polarity in planarians. Development 2015, 142, 1062-1072. [CrossRef]

37. Petersen, C.P.; Reddien, P.W. Polarized notum activation at wounds inhibits Wnt function to promote planarian head regeneration. Science 2011, 332, 852-855. [CrossRef]

38. Iglesias, M.; Almuedo-Castillo, M.; Aboobaker, A.A.; Salo, E. Early planarian brain regeneration is independent of blastema polarity mediated by the Wnt/beta-catenin pathway. Dev. Biol. 2011, 358, 68-78. [CrossRef]

39. Yazawa, S.; Umesono, Y.; Hayashi, T.; Tarui, H.; Agata, K. Planarian Hedgehog/Patched establishes anterior-posterior polarity by regulating Wnt signaling. Proc. Natl. Acad. Sci. USA 2009, 106, 22329-22334. [CrossRef] [PubMed]

40. Adell, T.; Salo, E.; Boutros, M.; Bartscherer, K. Smed-Evi/Wntless is required for beta-catenin-dependent and -independent processes during planarian regeneration. Development 2009, 136, 905-910. [CrossRef]

41. Nogi, T.; Watanabe, K. Position-specific and non-colinear expression of the planarian posterior (Abdominal-B-like) gene. Dev. Growth Differ. 2001, 43, 177-184. [CrossRef]

42. Thiruvalluvan, M.; Barghouth, P.G.; Tsur, A.; Broday, L.; Oviedo, N.J. SUMOylation controls stem cell proliferation and regional cell death through Hedgehog signaling in planarians. Cell Mol. Life Sci. 2018, 75, 1285-1301. [CrossRef] [PubMed]

43. Henderson, J.M.; Nisperos, S.V.; Weeks, J.; Ghulam, M.; Marin, I.; Zayas, R.M. Identification of HECT E3 ubiquitin ligase family genes involved in stem cell regulation and regeneration in planarians. Dev. Biol. 2015, 404, 21-34. [CrossRef]

44. Strand, N.S.; Allen, J.M.; Ghulam, M.; Taylor, M.R.; Munday, R.K.; Carrillo, M.; Movsesyan, A.; Zayas, R.M. Dissecting the function of Cullin-RING ubiquitin ligase complex genes in planarian regeneration. Dev. Biol. 2018, 433, 210-217. [CrossRef]

45. Novellasdemunt, L.; Kucharska, A.; Jamieson, C.; Prange-Barczynska, M.; Baulies, A.; Antas, P.; van der Vaart, J.; Gehart, H.; Maurice, M.M.; Li, V.S. NEDD4 and NEDD4L regulate Wnt signalling and intestinal stem cell priming by degrading LGR5 receptor. EMBO J. 2020, 39, e102771. [CrossRef] [PubMed]

46. Ding, Y.; Zhang, Y.; Xu, C.; Tao, Q.H.; Chen, Y.G. HECT domain-containing E3 ubiquitin ligase NEDD4L negatively regulates Wnt signaling by targeting dishevelled for proteasomal degradation. J. Biol. Chem. 2013, 288, 8289-8298. [CrossRef]

47. Reddien, P.W. Positional Information and Stem Cells Combine to Result in Planarian Regeneration. Cold Spring Harb. Perspect Biol. 2021, a040717. [CrossRef]

48. Tian, Q.N.; Bao, Z.X.; Lu, P.; Qin, Y.F.; Chen, S.J.; Liang, F.; Mai, J.; Zhao, J.M.; Zhu, Z.Y.; Zhang, Y.Z.; et al. Differential expression of microRNA patterns in planarian normal and regenerative tissues. Mol. Biol. Rep. 2012, 39, 2653-2658. [CrossRef] [PubMed]

49. Guo, Q.; Zhao, G.; Ni, J.; Guo, Y.; Zhang, Y.; Tian, Q.; Zhang, S. Down-regulate of Djrfc2 causes tissues hypertrophy during planarian regeneration. Biochem. Biophys. Res. Commun. 2017, 493, 1224-1229. [CrossRef]

50. Rouhana, L.; Weiss, J.A.; Forsthoefel, D.J.; Lee, H.; King, R.S.; Inoue, T.; Shibata, N.; Agata, K.; Newmark, P.A. RNA interference by feeding in vitro-synthesized double-stranded RNA to planarians: Methodology and dynamics. Dev. Dyn 2013, 242, 718-730. [CrossRef]

51. Pearson, B.J.; Eisenhoffer, G.T.; Gurley, K.A.; Rink, J.C.; Miller, D.E.; Sanchez Alvarado, A. Formaldehyde-based whole-mount in situ hybridization method for planarians. Dev. Dyn 2009, 238, 443-450. [CrossRef] [PubMed]

52. Cebria, F.; Newmark, P.A. Planarian homologs of netrin and netrin receptor are required for proper regeneration of the central nervous system and the maintenance of nervous system architecture. Development 2005, 132, 3691-3703. [CrossRef] [PubMed]

53. Qin, Y.F.; Fang, H.M.; Tian, Q.N.; Bao, Z.X.; Lu, P.; Zhao, J.M.; Mai, J.; Zhu, Z.Y.; Shu, L.L.; Zhao, L.; et al. Transcriptome profiling and digital gene expression by deep-sequencing in normal/regenerative tissues of planarian Dugesia japonica. Genomics 2011, 97, 364-371. [CrossRef] [PubMed] 